\title{
Standardization of the Tomographic Procedures in Cranio-facial Region
}

\author{
by \\ Shoichi ANDO*, Mituhisa OZAWA* and Hiroyoshi YAMANO*
}

\section{Introduction}

A prominent problem encountered in the current radiographic techniques is that there are in use various methods concerning the positioning of central ray and the situation is rendered more complex as a method has to be selected in accordance with a symptom presented. An accurate positioning of central ray is considered quite necessary to obtain a radiogram which is distinct enough from any other part of the body, since the cranio-facial region has highly complicated bone structures.

On the other hand, what is known as tomography is available which makes it possible to select and radiograph any one layer of a certain depth of an object, the remaining structures of different layers being blurred in the pale and amorphous state.

As is the case with other radiographic rules, however, we must observe a very careful positioning of central ray with this tomographic technique. Otherwise, we fail to obtain a good diagnostic effect.

The authors are concerned in this paper with a new device of a standardized equipment which has successfully improved the difficulties involved in tomographic radiography.

\section{Fundamental Consideration of Our New Device}

\subsection{Essentials of tomography.}

Tomography or body-section radiography is a general term applied in techniques that provide a disintact image of a selected layer of issue in the body while the images of structures that lie on either side of the selected layer are blurred. This effect is obtained by a mechanism that moves the $\mathrm{x}$-ray tube and the film simultaenously in opposite directions, or it can be accomplished by rotating the body and the film while the tube remains stationary. A number of distinguishing names have been given to different variations of these techniques. A few of the more common terms are laminagraphy, planigraphy, stratigraphy and vertigraphy. The differences among them involve primarily the paths of movement of the tube and film (whether they are rectilinear or circular) and the inclination of the film (whether it is at right angles or inclined) relative to the central ray.

In tomography (Fig. 1), the film and the tube are rotated about a pivot point (P)

\footnotetext{
*安藤 正一, *尾沢 光久, *山野 博司: Dept. of Radiology, Nihon Univ. School of Dentistry, Chiyoda-ku, Tokyo.

The gist of the present investigation was read before the 26th general meeting of Nippon Societas Radiologica for 1967, Gifu City.
} 


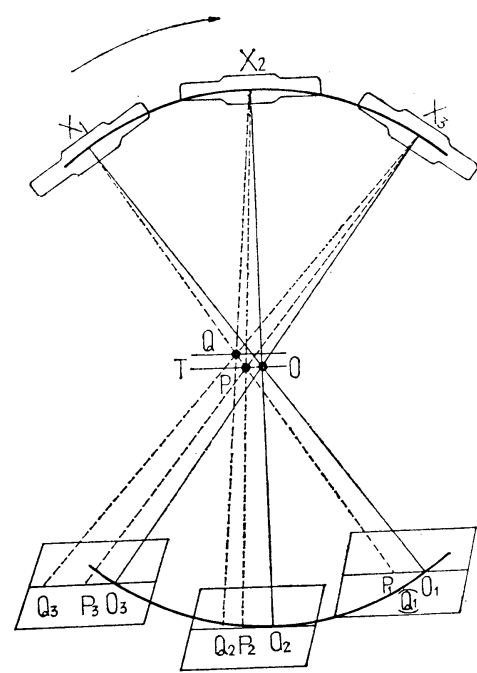

Fig. 1. Diagram showing basic principle of tomography

which is situated at the selected plane of tissue (T-P-O). Throughout the movement, the image of a structure level with the pivot point is recorded on the same area of the film and is thus distinctly recorded. The images of structures which are not in that plane are recorded in a series of positions on the film and thus appear blurred $\left(\mathbf{Q}, \mathbf{Q}_{1}-\mathbf{Q}_{2}-\mathbf{Q}_{3}\right)$. The pivot point determines the layer of tissue which will be distinctly recorded on the film. Even though the film and the tube move during the exposure, the selected plane of tissue remains stationary relative to the tube and the film. Therefore, in so far as the selected plane of tissue is concerned, the procedure is not appreciably different from conventional radiography. The movement, however, produces a blurring of the images of structures which are not in the selected plane because these structures are not stationary relative to the tube and the film. Thus, it becomes apparent in body-section techniques we are not dealing with some strange phenomenon. We are using movement to cause blurring of structures which interfere with the areas that we want to examine, while permitting a distinct recording of the desired structures.

\subsection{New tomographic technique by circular orbit path.}

As is stated in the preceding section, the angle of movement of the tube and the film around the pivot is within a range of 40 to $50^{\circ}$. Movement beyond this angle

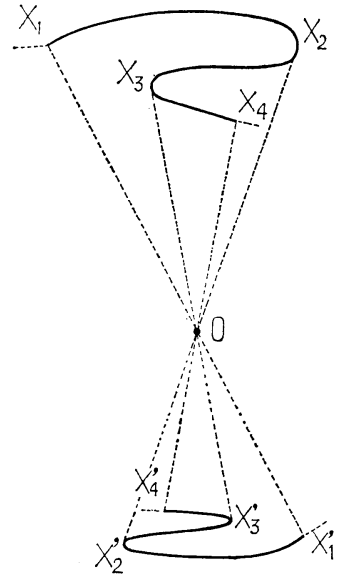

Fig. 2. Diagram showing basic principle of circus tomography

Note: $\mathrm{X}_{1} . \mathrm{X}_{2} . \mathrm{X}_{3} \ldots$. locations of $\mathrm{X}$-ray tube, $\mathrm{X}^{\prime}{ }_{1 .}-\mathrm{X}^{\prime}{ }_{2 .}-\mathrm{X}^{\prime}{ }_{3}-\ldots$ translating path of film.

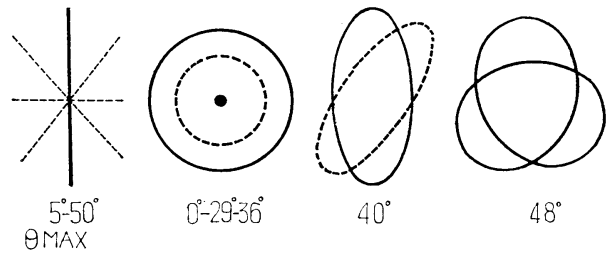

Fig. 3. Diagram showing of several trajectory in "Polytome"

- Linear, circular, elliptical, hypocycoidal and for zonography - (TOBB et al.).

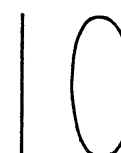

$18^{\circ} 30^{\circ}$ $\theta \operatorname{MAX}$

Fig. 4. Diagram showing of several trajectory in "Roulettes Tomography" (MATSUKAWA). 
is limited by the mechanical construction and, when it should be attempted, it will result in obtaining a poor radiographic image. In order to enhance the tomographic effect, therefore, we can obtain a better radiographic pattern when it is possible to have a longer orbit path within the angles of 40 to $50^{\circ}$.

To fulfil this requirement, there have been developed two techniques of linear tomography and circus tomography. With the former technique, the thickness of a layer of structure to be observed is about $10 \mathrm{~mm}$, but, according to our new method, it is possible to obtain a clear radiographic pattern of a layer as thin as $1 \mathrm{~mm}$.

This possibility is particularly useful in diagnosing the structures in cranio-facial region as this region consists of numerous thin bones that are piled up in a very complex manner.

A schematic illustration of this orbit path is given in Fig. 2. In the figure, $\mathbf{X}_{1,2,3,4}$ indicates movement of the tube and $\mathbf{X}_{1,2,3,4}^{\prime}$ indicates the sequence in which point 0 projects itself on the film.

Similarly, Figs. 3 and 4 respectively give schematic illustrations of orbit paths peculiar to the polytome and roulette tomography equipment.

\section{Procedure and Mechanism}

\subsection{Joint use of standardized equipment with Polytome and other circus tomography apparatus.}

In using Polytome and other tomographic techniques, the plane on which a radio-

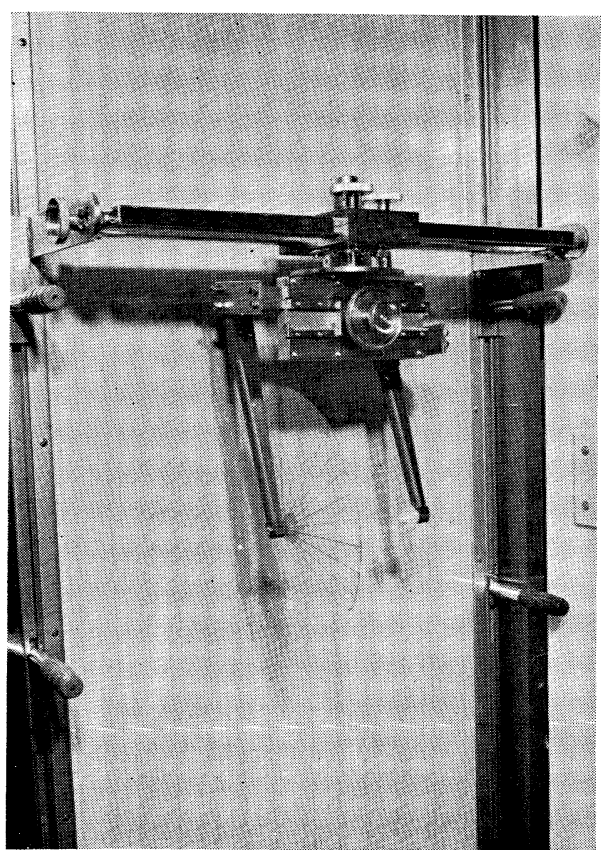

Fig. 5. Newly devised cephalostat for standardizing technique in the positioning procedure on "Polytome" graphic pattern is obtained should correspond to the height of the pivot of its mechanism. Necessary positioning is achieved by means of an attached special

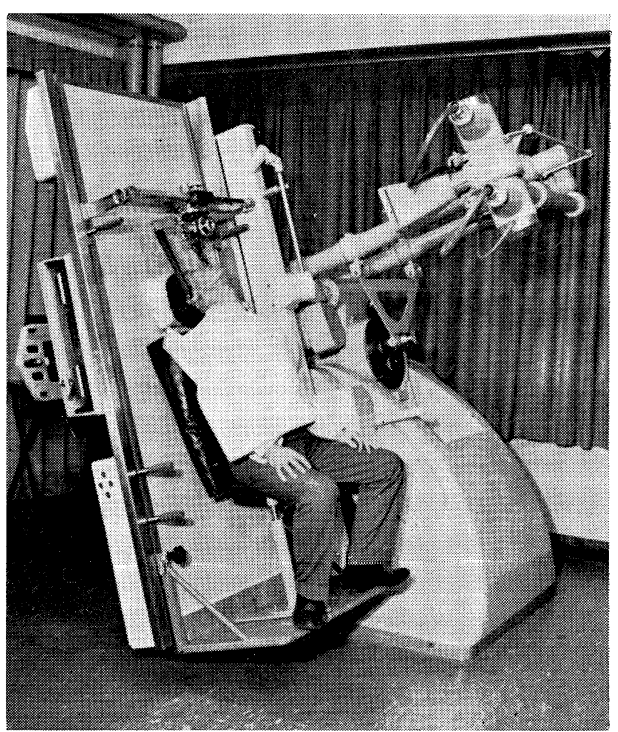

Fig. 6. Application of newly devised cephalostat of "Polytome" 
scale and a measure which is built in the apparatus. However, use of these attachments alone often tends to reduce the desired accuracy.

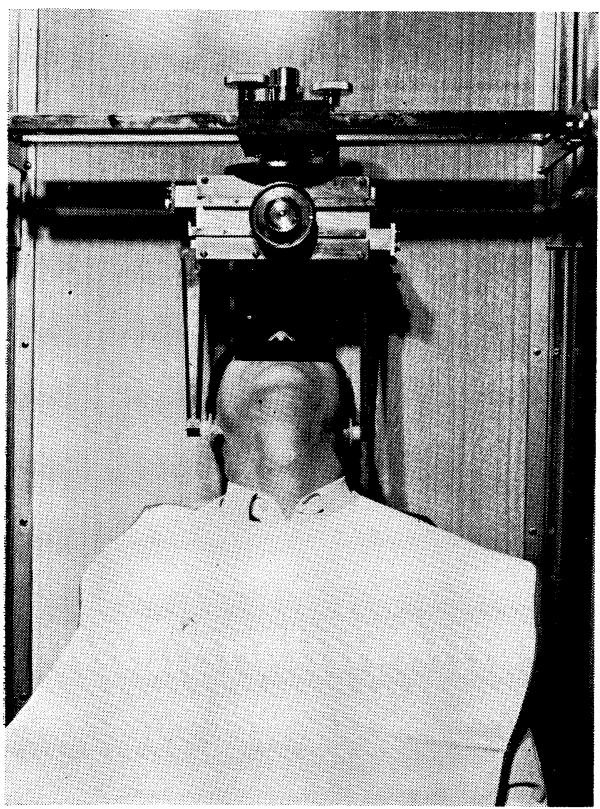

Fig. 7. Positioning for mento-vertex projection

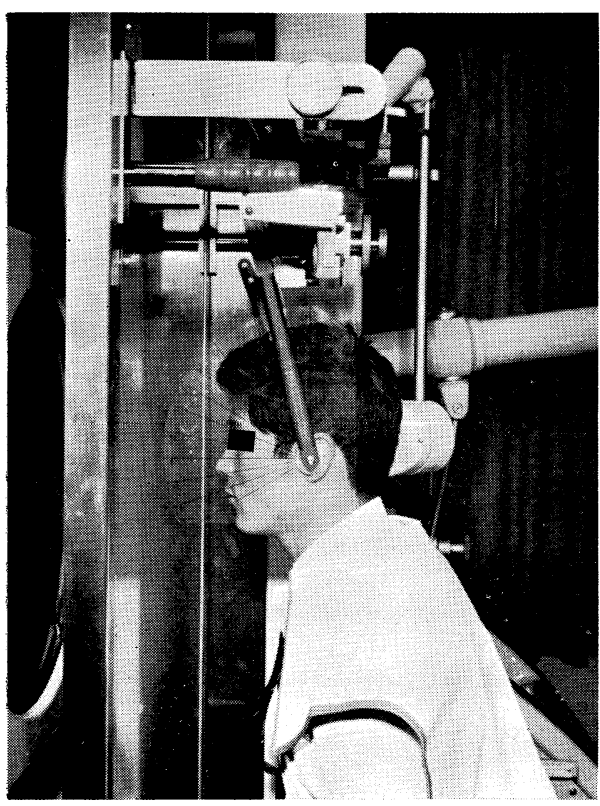

Fig. 8. Positioning for occipito-frontal projection

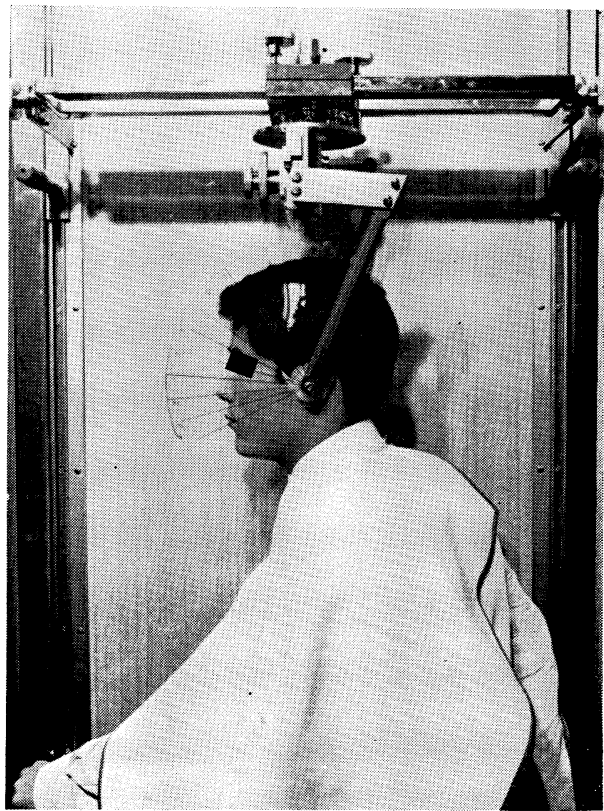

Fig. 9. Positioning for lateral projection

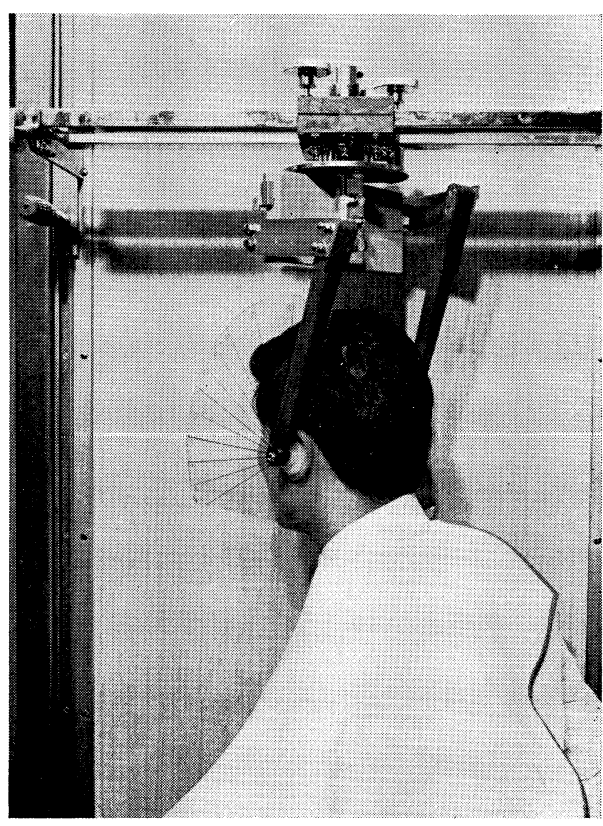

Fig. 10. Positioning for oblique projection 
Selected tomographic patterns produced by hypocycoidal movement; Occipito-frontal projection

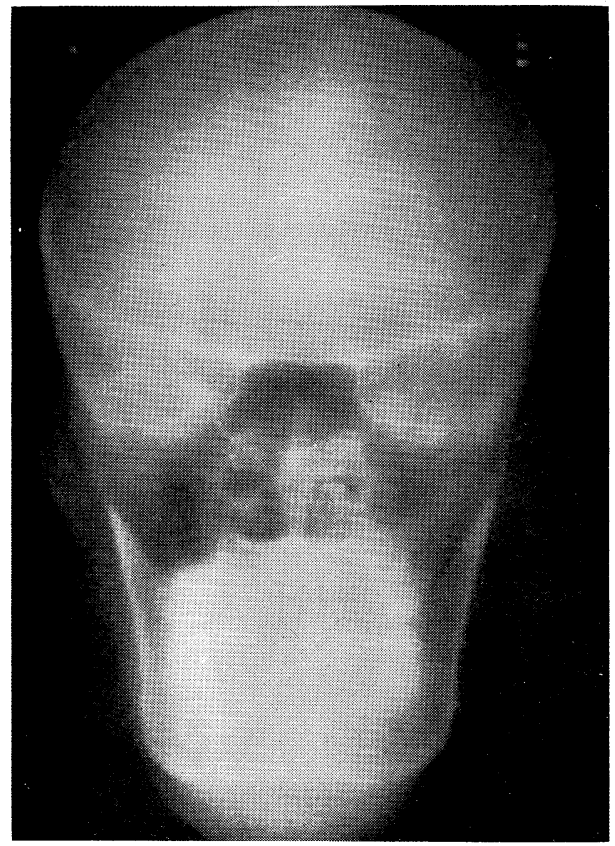

Fig. 11. Nearer layer to film-side, $-5 \mathrm{~cm}$ -

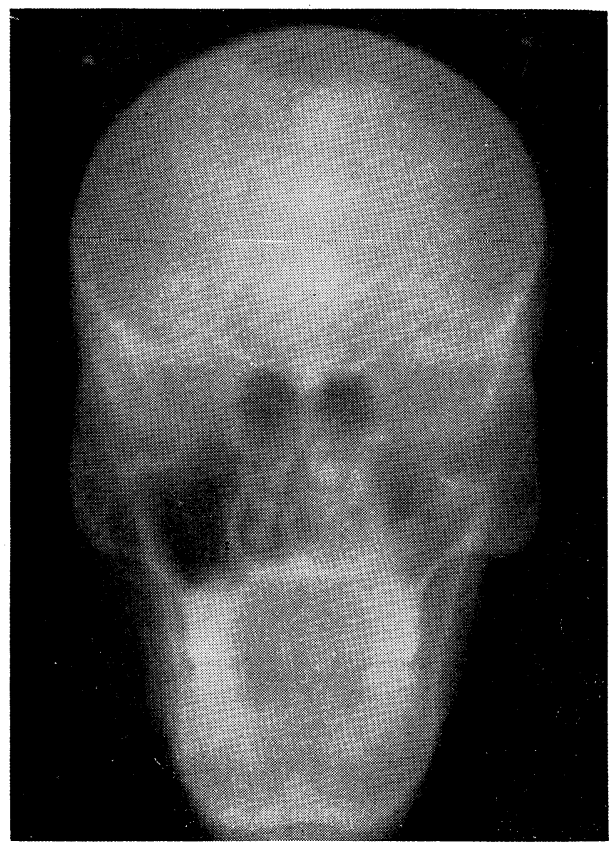

Fig. 12. Film-side, $-6 \mathrm{~cm}-$

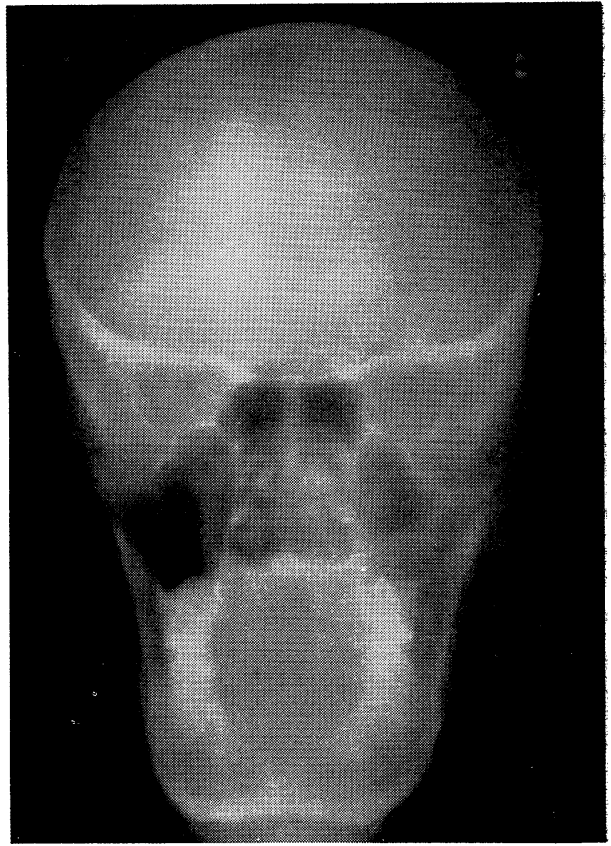

Fig. 13. Film-side, $-7 \mathrm{~cm}$ -

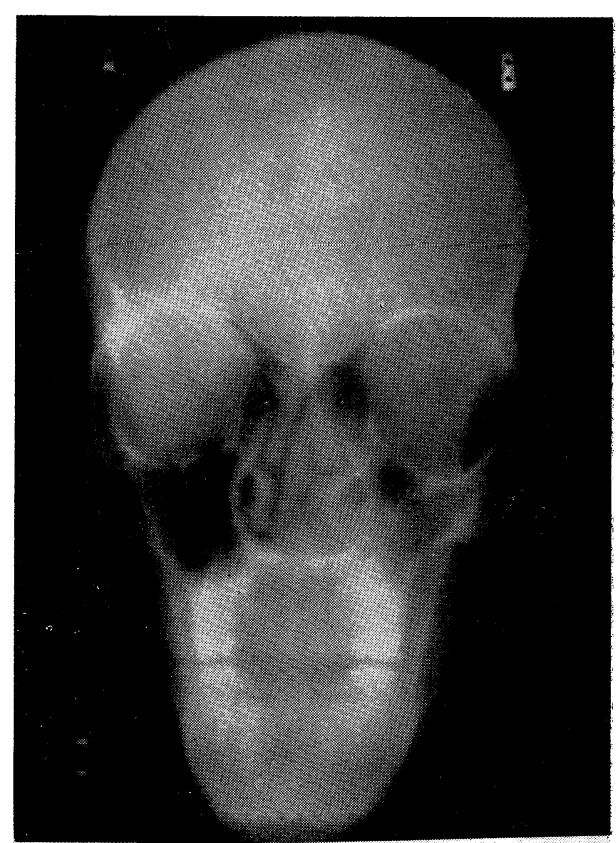

Fig. 14. Film-side, $-8 \mathrm{~cm}$ - 
Selected tomographic pattern, hypocycoidal ; Lateral projection

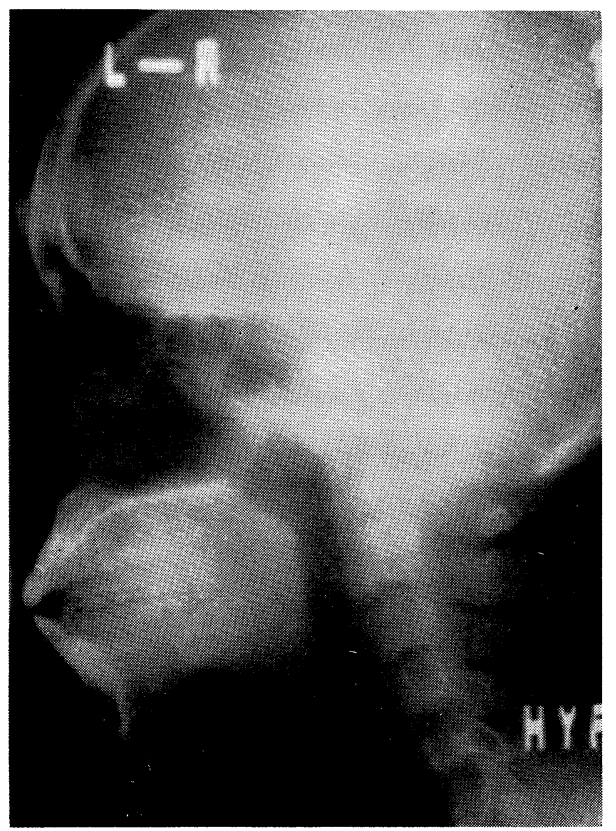

Fig. 15. Nearer layer to film-side, $-1 \mathrm{~cm}$ -

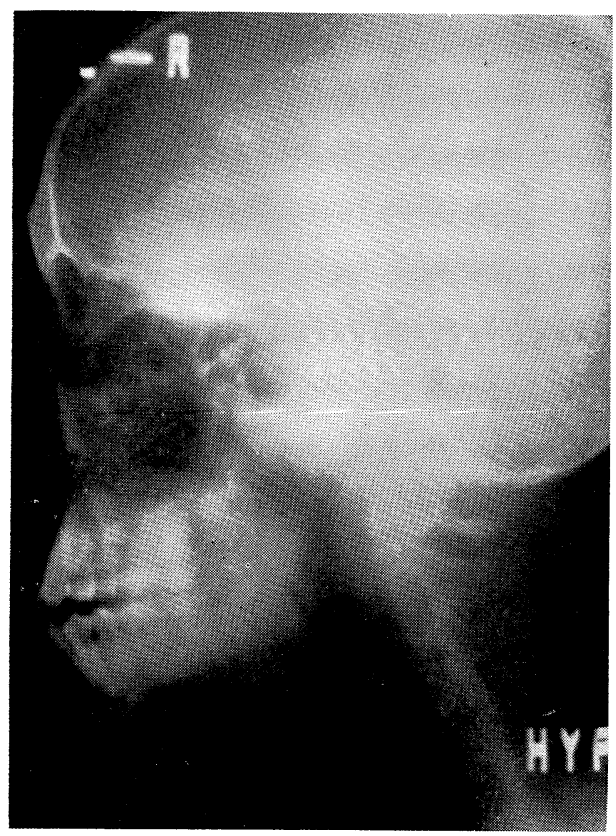

Fig. 16. Film-side, $-2 \mathrm{~cm}$ -

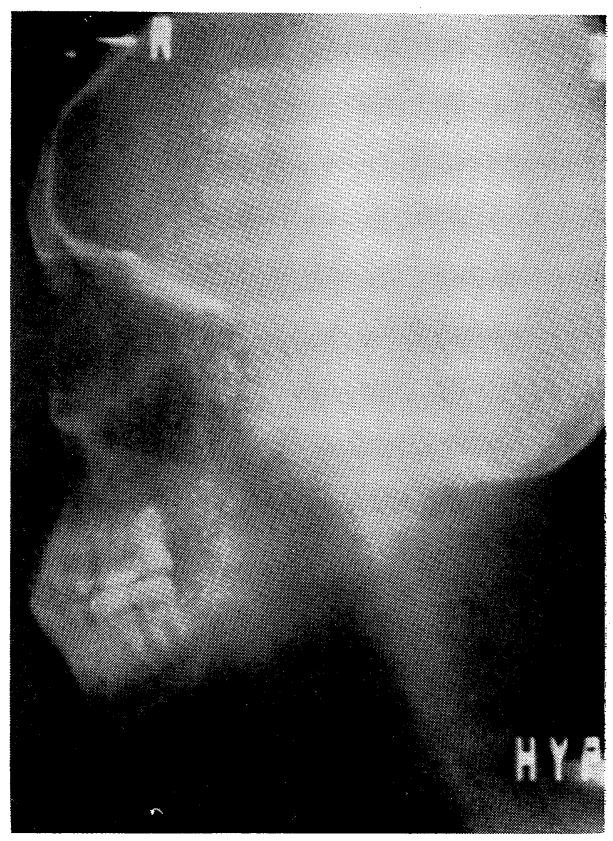

Fig. 17. Film-side, $-3 \mathrm{~cm}-$

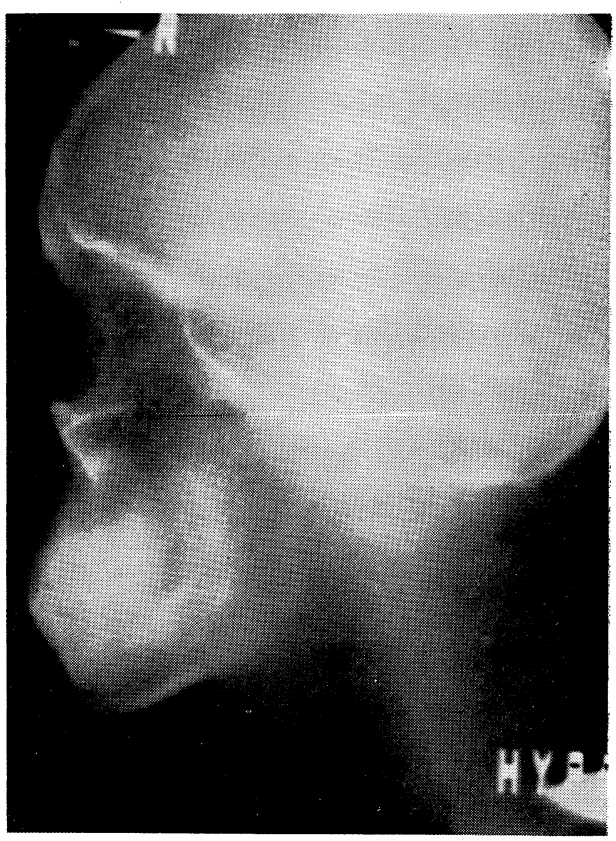

Fig. 18. Film-side, $-4 \mathrm{~cm}$ - 
Selected tomographic pattern, hypocycoidal; Oblique projection

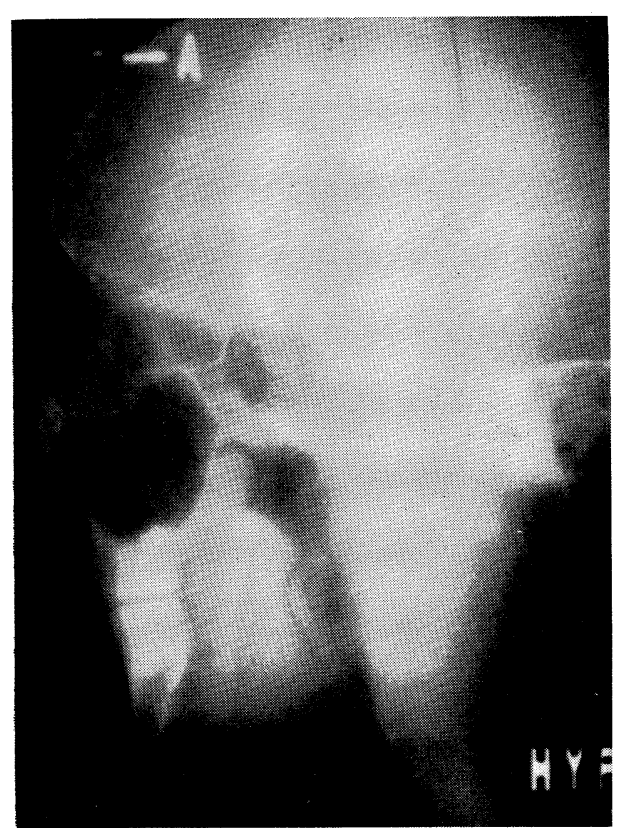

Fig. 19. Nearer layer to film-side, $-3 \mathrm{~cm}$ -

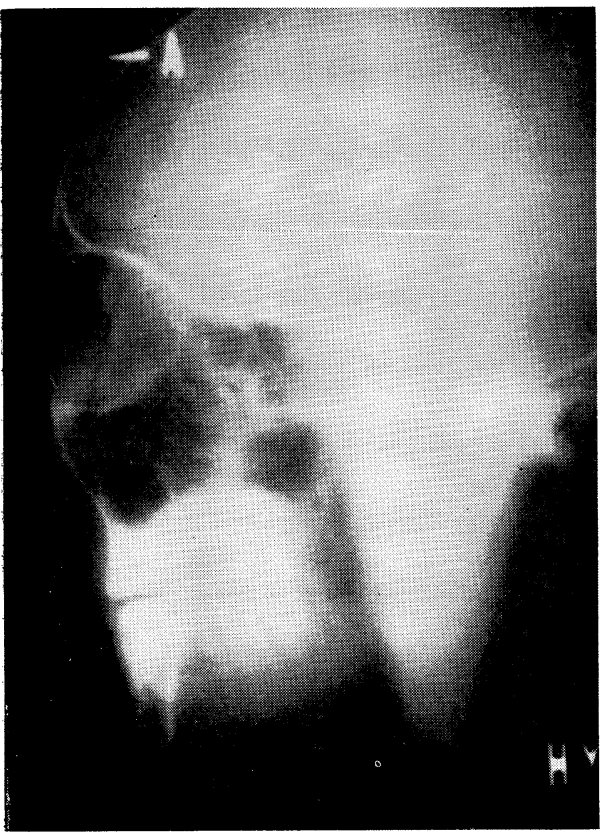

Fig. 20. Film-side, $-4 \mathrm{~cm}$ -

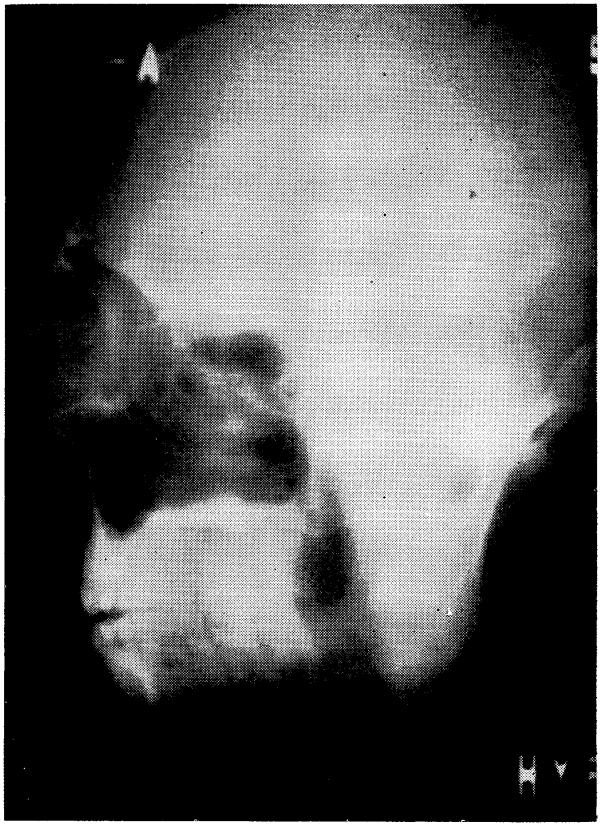

Fig. 21. Film-side, $-5 \mathrm{~cm}$ -

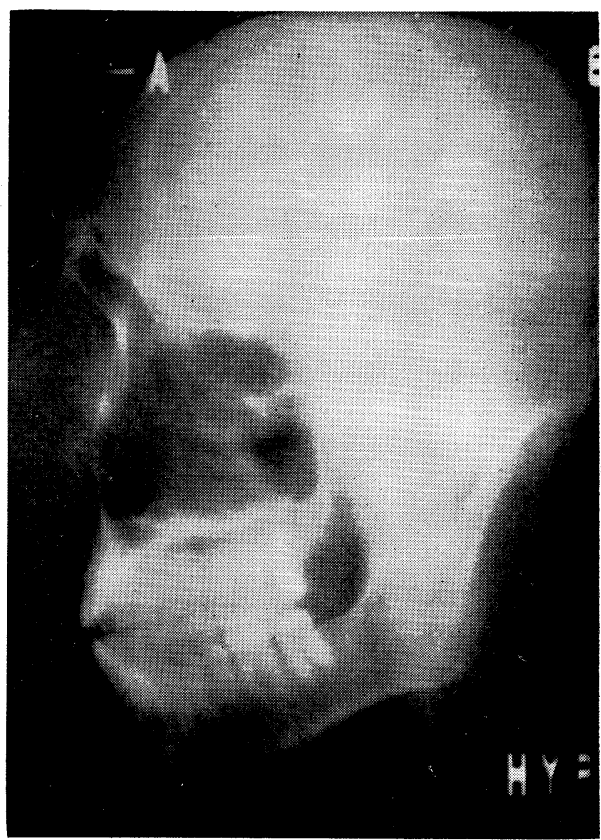

Fig. 22. Film-side, $-6 \mathrm{~cm}$ - 
Selected tomographic pattern, hypocycoidal ; Mento-vertex projection

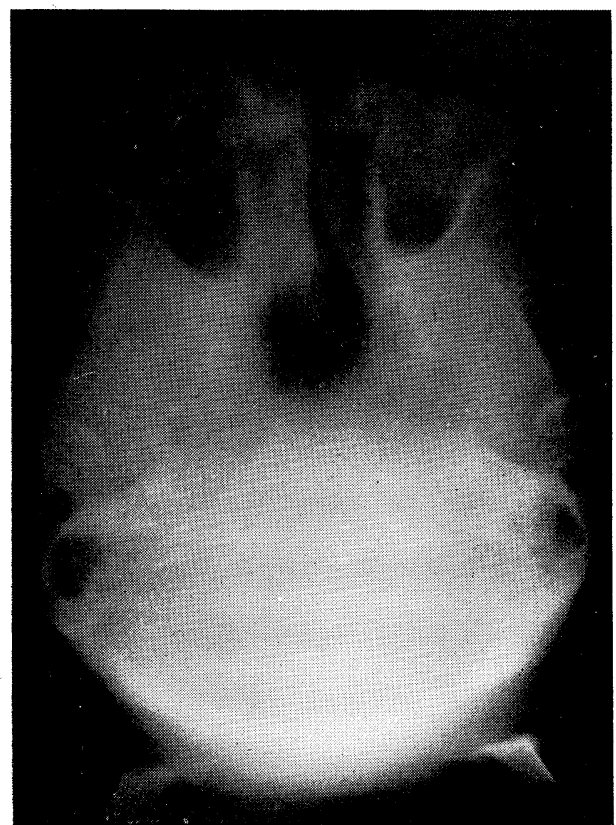

Fig. 23. Basic layer of standardizing procedure $(=0)$

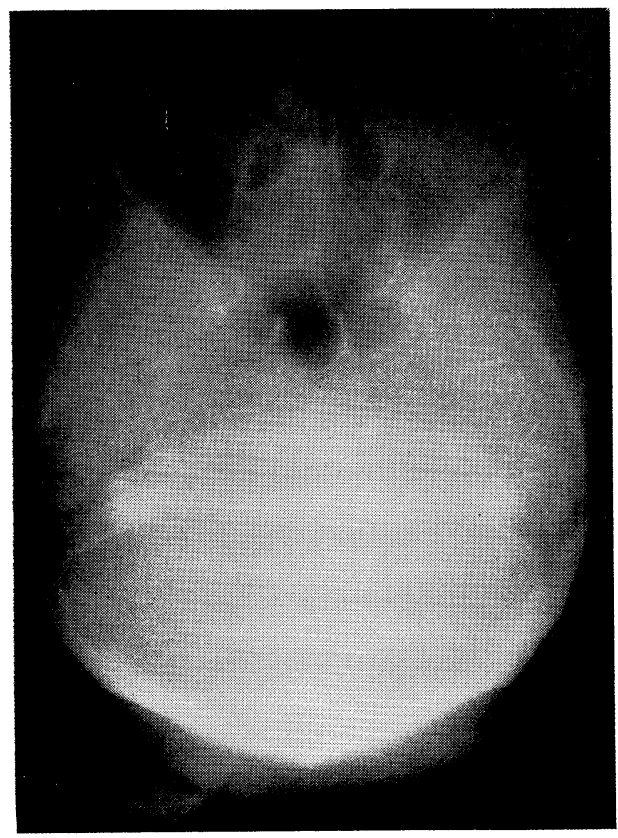

Fig. 24. Nearer layer to film-side, $-2 \mathrm{~cm}$ -

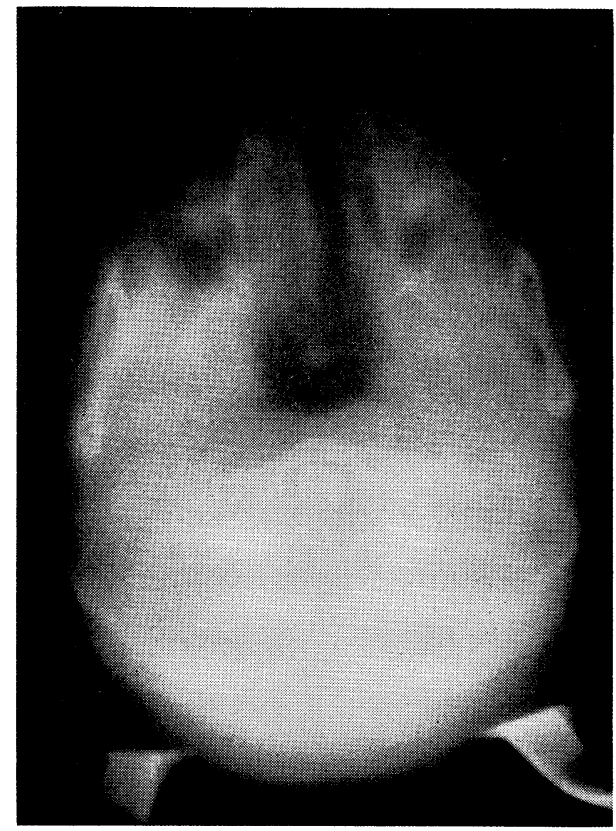

Fig. 25. Nearer layer to tube-side, $-2 \mathrm{~cm}$ -

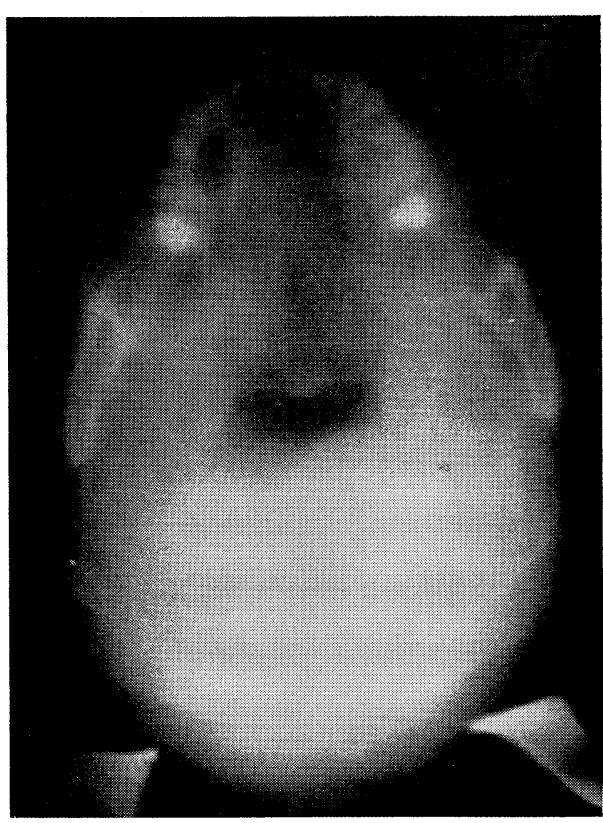

Fig. 26. Tube-side, $-3 \mathrm{~cm}$ - 
In order to improve on the accuracy we newly designed a cephalostat which, by means of the ear-rods on bilateral external auditory meatuses of a patient to be radio graphed, is capable of accurately positioning the trajectories on his cranio-facial region.

Fig. 5 shows this new standardized equipment of ours attached to the Polytome table. In the figure, 1) indicates the support for a cephalostat which is constructed to fit the grooves on both sides of the table and 2) is the involution gear to position the patient's head accurately in the center by moving the ear-rods to right and left.

A basic plane linking the two ear-rods can be adjusted to be in parallel, at right angle or in the middle position to the plane of the film at the time of radiography.

In this manner, it has bocome possible to position the head region of a patient in 1) occipito-frontal and fronto-occipital directions, 2) lateral direction, 3) oblique direction, and 4) mento-vertical direction.

Figs. 6 to 10 give the illustrations of positioning in all these directions.

\section{Results and Their Evaluation}

Standardized tomograms taken by the use of this cephalostat are shown in Figs. 11 to 26 , Their breakdown is as follows.

Figs. 11 to 14 . Occipito-frontal direction

Figs. 15 to 18 . Lateral direction

Figs. 19 to 22 . Oblique direction at $45^{\circ}$

Figs. 23 to 26 . Mento-vertical direction

All of these tomograms, taken of the same patient, show various layers of different depths. When these are compared, it is evident that they clearly show the structures in different layers and thus we are enabled to obtain definite radiographic patterns. It is necessary that this kind of equipment should be added to standardized procedures to obtain satisfactory results. By observing these procedures, it is possible to achieve the observation of fine bone structures, comparison of various forms and measurement of the jaw movement. At the same time, the use of standardized tomograms taken by this method helps us in determining accurately a dose distribution in therapeutic irradiation techniques of the malignant tumors.

\section{Conclusion}

The authors have successfully devised a new cephalostat which is capable of accurately positioning the cranio-facial region of a patient on the Polytome and, at the same time, of reproducing these positions thus determined.

The application of this cephalostat was demonstrated in the occipito-frontal and fronto-occipital directions, lateral direction, oblique direction and mento-vertical direction. Modifications of these procedures are also possible when such is indicated.

\section{References}

[1] Tовв ; Le Polytome de MM. Sans et Porcher, J. radiol, électrol. 31: 300-302, 1950 1950 (cited from Matsukawa, A. and Mishina, H. : Diagnostic Radiology, p. 109, Nanzan-do, Tokyo, 1967).

[2] Matsukawa, A. : Improvemental processes in tomographic procedure, Nippon Acta Radiologica, 20 : 2167-2190, 1960. 
[3] ANDO, S. et al. : Special technique in radiography.-Tomography in cranio-facial region-. Dental Outlook, 26 : 1119-1125, 1965. (in Japanese)

[4] Westra, D.: Zonography.-Narrow-angle tomography--; Exepta Media Foundation. Amsterdam, New York, London, Milan, Tokyo, Buenos Aires, 1966.

[5] Philips, J. E. : Principles and function of the orthopantomograph. Oral Surg., oral Med. \& oral Path, Vol. 24 : 41-49, 1967. 